ARTIKEL PENELITIAN

\title{
PENGARUH PENDIDIKAN KESEHATAN KANKER SERVIKS TERHADAP PENGETAHUAN DAN MINAT MELAKUKAN PEMERIKSAAN IVA PADA WUS DI WILAYAH KELURAHAN SEPINGGAN BALIKPAPAN TAHUN 2017
}

\author{
Ni Nyoman Murti ${ }^{1}$, Faridah Hariyani ${ }^{2}$ \\ 1)2) Jurusan Kebidanan Prodi DIII Kebidanan Balikpapan Politeknik Kesehatan \\ Kementerian Kesehatan Kalimantan Timur, Indonesia \\ Email : baratamurti@gmail.com
}

\begin{abstract}
Cancer cases are increasing every year and the costs incurred for cancer treatment are getting bigger so there is a need to prevent cancer prevention, one of them is through IVA examination. Given the importance of examining IVA to detect early cervical cancer in an effort to reduce the incidence and death of cervical cancer. Knowledge is an important factor for generating early detection behaviours. One of the efforts is to increase community knowledge and interest by using counselling. This study uses a quantitative approach. The method used in this study is quasi-experimental or quasiexperimental. The design of this study used a randomized two-group design. This design aims to see the magnitude of the effect of treatment given to the experimental group given health education and the control group given leaflets. The population in this study were all 5,900 women of childbearing age (WUS) who had or had been married as much as 5,900 people. The sampling technique was done by cluster random sampling technique as many as 80 respondents consisting of 40 experimental samples and 40 control samples. The measuring instrument used in this study was a questionnaire to measure the knowledge and interest of mothers in conducting IVA examinations. The statistical test used in this study uses Independent T-Test. The result of the study is that there is a difference in WUS knowledge about cervical cancer in the group given Health Education and the group given the leaflet/brochure is indicated by the p-value of 0,000 . There is a difference in the interest of WUS in examining the IVA in the group given Health Education and the group given the leaflet/brochure is indicated by the p-value of 0.000 .
\end{abstract}

Keywords: Health Education, IVA Test, Interest

\begin{abstract}
Abstrak
Kasus penyakit kanker bertambah setiap tahun dan biaya yang ditanggung untuk pengobatan kanker semakin besar sehingga perlu adanya tiondakan pencegahan penyakit kanker salah sarunya melalui pemeriksaan IVA. Mengingat betapa pentingnya pemeriksaan IVA untuk mendeteksi dini untuk kanker serviks dalam upaya menurunkan insiden dan kematian akibat kanker serviks. Pengetahuan merupakan faktor yang penting untuk menimbulkan perilaku deteksi dini.salah satu upaya untuk meningkatkan pengetahuan dan minat masyarakat yaitu dengan menggunakan penyuluhan. Penelitian ini menggunakan pendekatan kuantitatif. Metode yang digunakan dalam penelitian ini adalan quasi eksperimen atau eksperimen semu. Rancangan penelitian ini menggunakan randomized two group design. Rancangan ini bertujuan untuk melihat besarnya pengaruh perlakuan yang diberikan pada kelompok eksperimen yang diberikan pendidikan kesehatan dan kelompok kontrol yang diberikan leaflet. Populasi dalam penelitian ini adalah semua wanita usia subur (WUS) yang sudah atau pernah menikah sebanyak 5.900 orang.Teknik pengambilan sampel dilakukan dengan teknik cluster random sampling sebanyak 80
\end{abstract}


responden terdiri dari 40 sampel eksperimen dan 40 sampel kontrol. Alat ukur yang digunakan dalam penelitian ini kuisioner untuk mengukur pengetahuan dan minat ibu melakukan pemeriksaan IVA. Uji statistik yang digunakan dalam penelitian ini menggunakan Uji T Independen. Hasil penelitian ada perbedaan Pengetahuan WUS tentang kanker serviks pada kelompok yang diberikan Pendidikan Kesehatan dan kelompok yang diberikan leaflet/brosur ditunjukkan dengan nilai $\mathrm{p}$ value 0,000 . Ada perbedaan minat WUS melakukan pemeriksaan IVA pada kelompok yang diberikan Pendidikan Kesehatan dan kelompok yang diberikan leaflet/brosur ditunjukkan dengan nilai $\mathrm{p}$ value 0.000 .

Kata Kunci : Pendidikan Kesehatan, Pemeriksaan IVA, Minat

\section{PENDAHULUAN}

Kasus penyakit kanker terus bertambah setiap tahun, penyakit inipun mengalami kenaikan pada tahun 2016 hingga menempati posisi ketiga setelah jantung dan gagal ginjal. Kepala Grup Manajemen Pelayanan kesehatan primer BPJS Kesehatan Fahrurrazi menyampaikan ,jumlah kasus kanker yang ditanggung pembiayaanya pada 2016 1.308 juta kasus.Pada periode Desember 2015 hingga Nopember 2016 tercatat ada 150.243 kasus kemoterapi ringan, sedang dan berat yang memakan biaya hingga $\mathrm{Rp}$ 573 miliar. Direktur Jendral Pencegahan dan Pengendalian Penyakit Kementerian Kesehatan (Kemenkes) Muhamad Subuh membenarkan, prevalensi penyakit kanker di Indonesia yang cukup tinggi, data Rikesdas 2013,prevalensi tumor/kanker di Indonesia adalah 1,4 per 1000 penduduk, atau sekitar 347.000 orang. Dimana kasus tertinggi pada perempuan adalah kanker payudara dan kanker leher
rahim.Pemerintah tengah menekankan upaya deteksi dini kanker pada perempuan berupa skrining kanker rahim dengan metode inspeksi visual dengan asam asetat (IVA). Pada 2016, cakupan deteksi dini IVA di Indonesia diketahui meningkat dibandingkan tahun 2015.Subuh menuturkan,ada beberapa faktor risiko yang dapat memicu kanker,yakni, perilaku hidup, pola makan,dan genetik (Kaltim Pos, 2017).

Kementrian Kesehatan bekerjasama dengan Female Cancer Program (FCP), Yayasan Kanker Indonesia(YKI), BKKBN, Inisiasi Pencegahan Kanker Serviks Indonesia (IPKASI), AsiaOceania Research Organization in Genital Infection And Neoplasia (AOGIN),Perguruan Tinggi, Masyarakat, dan Pemerintah daerah untuk menggalakkan program yang bertujuan untuk menurunkan angka kesakitan dan kematian akibat kanker serta meningkatkan kualitas hidup penderita 
kanker. Kegiatan ini menggunakan metode Inspeksi Visual dengan Asam Asetat (IVA) atau dengan Papa smear oleh petugas kesehatan yang sudah terlatih. Langkah ini yang dilakukannyaitu dengan dikeluarkannya Surat Keputusan Menteri Kesehatan No 1163/MENKES/SK/X/2007 tentang kelompok kerja pengendalian penyakit kanker leher rahim dan payudara (Depkes RI,2005).

Kesadaran masyarakat untuk memeriksakan diri sejak dini dirasakan sangat rendah. Selain itu, masyarakatmerasa pemeriksaan pap smear dianggap tabu, ibu merasa malu untuk melakukan pemeriksaan. Indikasinya adalah lebih dari $70 \%$ penderita yang datang kerumah sakit sudah pada stadium lanjut.Seluruh masyarakat harusnya terlibat dalam upaya program pencegahan terhadap kanker serviks (Novel, 2010).

Salah satu upaya untuk meningkatkan pengetahuan dan minat masyarakat yaitu dengan menggunakan penyuluhan. Penekanan konsep penyuluhan kesehatan lebih pada upaya mengubah perilakun sasaran agar berperilaku sehat terutama pada aspek kognitif (pengetahuan dan pemahaman sasaran), sehingga pengetahuan sasaran penyuluhan telah sesuai dengan yangb diharapkan oleh penyuluh kesehatan maka penyuluhan berikutnya akan dijalankan sesuai dengan program yangtelah direncanakan (Maulana, 2009).

Berdasarkan studi pendahuluan di Dinas Kesehatan Kota Balikpapan didapatkan bahwa jumlah Puskesmas yang berada di Wilayah Kota Balikpapan ada 28 Puskesmas. Dari jumlah tersebut Puskesmas yang mempunyai wilayah paling luas adalah Puskesmas Sepinggan yang mebawahi 3 kelurahan yaitu kelurahan Sepinggan,Sepinggan baru dan Sepinggan raya dengan jumlah PUS 5900 (data BKKBN 2017). Dan hasil survey mahasiswa PKL selama 3 munggu pelaksanaan di 5 RT Kelurahan Sepinggan memperoleh data,dengan jumlah PUS ada 770, dan hasil analisis diperoleh "Kurangnya pengetahuan PUS tentang PMS \& kurangnya minat untuk melakukan IVA test ,ada sebanyak 675 (88\%) , dan hanya 95 (12\%) PUS yang tahu tentang PMSdan rata-rata setiap bulan yang melakukan pemeriksaan IVA hanya 4-5 orang saja (data KB). Maka dari latar belakang tersebut Peneliti tertarik untuk melakukan penelitian dengan judul'Pengaruh Pendidikan kesehatan kanker serviks terhadap pengetahuan \& minat melakukan pemeriksaan Inspeksi 
Visualdengan Asam Asetat (IVA) pada WUS di wilayah Puskesmas Sepinggan Balikpapan 2017.

\section{METODE PENELITIAN}

Penelitian ini merupakan penelitian kuantitatif, jenis penelitian case control yaitu suatu metode penelitian yang dilakukan dengan tujuan untuk membuat gambaran atau diskripsi tentang suatu keadaan secara objektif,kemudian menganalisis hubungan sebab akibat antara variable independent dan variable dependent (Notoatmodjo, 2010). Penelitian ini menggunakan metode quasi experiment dengan randomized two group design. Pengambilan sampel dilakukan secara acak dengan 2 kelompok perlakuan dimana kelompok eksperimen diberikan pendidikan kesehatan dan kelompok kontrol diberikan leaflet dan selanjutnya hasil perlakuan dibandingkan.

Tempat penelitian rencana akan dilakukan di Kelurahan Sepinggan Balikpapan. Waktu penelitian dimulai sejak pengambilan data untuk studi pendahuluan sampai penelitian dilaksanakan pada bulan Agustus sampai Oktober 2017.

Populasi dalam penelitian ini adalah seluruh Wanita Usia Subur yang telah atau pernah menikah di wilayah kelurahan Sepinggan Balikpapan yang berjumlah 5900 orang dari 67 RT. Teknik pengambilan sampel dalam penelitian ini menggunakan cluster random sampling. Jumlah sampel sebanyak 40 responden yang ditetapkan sebagai sampel eksperimen dan pengambilan sampel control menggunakan perbandingan $1: 1$ sehingga jumlah sampel kontrol sebanyak 40 orang dan jumlah sampel eksperimen sebanyak 40 orang sehingga jumlah seluruh sampel sebanyak 80 orang.

Variabel dalam penelitian ini terdiri atas : variabel independen (bebas) yaitu variabel yang mempengaruhi atau menjadi sebab perubahanya atau timbulnya variabel dependen. Variabel bebas dalam penelitian ini adalah Pendidikan Kesehatan sementara variabel dependen (terikat) yaitu variabel yang dipengaruhi atau yang menjadi akibat, karena adanya variabel bebas, yang menjadi variabel dependen dalam penelitian ini adalah Pengetahuan dan Minat.

Teknik pengumpulan data yang digunakan adalah angket (kuesioner tertutup yang berstruktur dengan bentuk pertanyaan favourable dan unfavourable) yang berupa beberapa pertanyaan kepada responden. 
Pelaksanaan analisis data menjelaskan sebaran data yang diperoleh menggunakan program computer. Analisis univariat digunakan untuk menjelaskan gambaran pengetahuan dengan menampilkan dalam bentuk histogram dan nilai mean, median, modus, standar deviasi serta minimal dan maksimal. Nilai-nilai tersebut digunakan untuk

\section{HASIL DAN PEMBAHASAN}

Hasil Analisis Univariat

\section{Karakteristik Responden}

Penelitian ini dilakukan pada 80 responden yang terdiri dari kelompok perlakuan dan kelompok kontrol. Hasil sehingga dapat menggambarkan hasil penelitian dengan lebih jelas, sementara analisis bivariat digunakan untuk mengetahui pengaruh pendidikan kesehatan kanker serviks terhadap pengetahuan dan minat melakukan pemeriksaan IVA pada WUS.

pengolahan data akan ditampilkan dalam bentuk tabel-tabel. Adapun table karakteristik responden sebagai berikut:

\section{a) Umur Responden}

Tabel 1.Karakteristik Responden Berdasarkan Umur Pada WUS

\begin{tabular}{ccccc}
\hline Umur Responden & \multicolumn{2}{c}{ Kelompok Eksperimen } & \multicolumn{2}{c}{ Kelompok Kontrol } \\
\cline { 2 - 5 } & Frekuensi & $\%$ & Frekuensi & $\mathbf{\%}$ \\
< 40 Tahun & 23 & 57.5 & 19 & $\mathbf{4 7 . 5}$ \\
$\geq \mathbf{4 0}$ Tahun & 17 & 47.5 & 21 & $\mathbf{5 2 . 5}$ \\
\hline Jumlah & $\mathbf{4 0}$ & $\mathbf{1 0 0}$ & $\mathbf{4 0}$ & $\mathbf{1 0 0}$ \\
\hline
\end{tabular}

Sumber : Pengolahan Data, 2017

$\begin{array}{lll}\text { Berdasarkan table. } 1 \text { dapat } & \text { orang }(57.5 \%) \text { begitu juga pada } \\ \text { ijelaskan bahwa pada kelompok } & \text { kelompok kontrol sebagian besar } \\ \text { experimen sebagian besar responden } & \text { berumur } \geq 40 \text { tahun yaitu } 21 \text { orang } \\ \text { erumur }<40 \text { tahun yaitu sebanyak } 23 & (52.5 \%) .\end{array}$




\section{b) Pendidikan Responden}

Tabel 2.Karakteristik Responden Berdasarkan Pendidikan Pada WUS

\begin{tabular}{ccccc}
\hline Pendidikan & \multicolumn{2}{c}{ Kelompok Eksperimen } & \multicolumn{2}{c}{ Kelompok Kontrol } \\
\cline { 2 - 5 } Responden & Frekuensi & $\%$ & Frekuensi & \% \\
SD & 5 & 12.5 & 6 & $\mathbf{1 5 . 0}$ \\
SMP & 13 & 32.5 & 7 & $\mathbf{1 7 . 5}$ \\
SMA & 18 & 45.0 & 20 & $\mathbf{5 0 . 0}$ \\
Diploma/PT & 4 & 10.0 & 7 & $\mathbf{1 7 . 5}$ \\
\hline Jumlah & $\mathbf{4 0}$ & $\mathbf{1 0 0}$ & $\mathbf{4 0}$ & $\mathbf{1 0 0}$ \\
\hline
\end{tabular}

Sumber : Pengolahan Data, 2017

Berdasarkan table.2 dapat dijelaskan bahwa pada kelompok eksperimen sebagian besar responden berpendidikan SMA yaitu 18 orang (45\%) dan paling sedikit responden yang berpendidikan
SD yaitu 5 orang $(12.5 \%)$ demikian juga pada kelompok kontrol sebagian besar responden berpendidikan SMA yaitu 18 orang $(45 \%)$ dan paling sedikit berpendidikan SD yaitu 6 orang $(15 \%)$.

\section{c) Pekerjaan Ibu}

Tabel 3.Karakteristik Responden Berdasarkan Pekerjaan Pada WUS

\begin{tabular}{ccccc}
\hline Pekerjaan Responden & \multicolumn{2}{c}{ Kelompok Eksperimen } & \multicolumn{2}{c}{ Kelompok Kontrol } \\
\cline { 2 - 5 } & Frekuensi & $\%$ & Frekuensi & \% \\
\hline PNS/ABRI & 6 & 15.0 & 9 & $\mathbf{2 2 . 5}$ \\
Guru/Dosen & 4 & 10.0 & 5 & $\mathbf{1 2 . 5}$ \\
Wiraswasta & 5 & 12.5 & 4 & $\mathbf{1 0 . 0}$ \\
Karyawan Swasta & 6 & 15.0 & 5 & $\mathbf{1 2 . 5}$ \\
Tidak Bekerja/IRT & 19 & 47.5 & 17 & $\mathbf{4 2 . 5}$ \\
\hline Jumlah & $\mathbf{4 0}$ & $\mathbf{1 0 0}$ & $\mathbf{4 0}$ & $\mathbf{1 0 0}$ \\
\hline
\end{tabular}

Sumber : Pengolahan Data, 2017

Berdasarkan tabel 3 dapat dijelaskan bahwa padakelompok eksperimen sebagian besar responden memiliki latar belakang sebagai IRT atau tidak bekerja 
yaitu 19 orang $(47.5 \%)$ dan paling sedikit responden dengan latar belakang guru/dosen yaitu 5 orang $(12.5 \%)$ demikian juga pada kelompok kontrol sebagian besar responden memiliki latar belakang sebagai IRT atau tidak bekerja yaitu 17 orang $(42.5 \%)$ dan paling sedikit dengan latar belakang pekerjaan wiraswasta yaitu 4 orang (10\%).

\section{d) Status Pernikahan}

Tabel 4. Karakteristik Responden Berdasarkan Status Pernikahan Pada WUS

\begin{tabular}{ccccc}
\hline \multirow{2}{*}{$\begin{array}{c}\text { Status Pernikahan } \\
\text { Responden }\end{array}$} & \multicolumn{2}{c}{ Kelompok Eksperimen } & \multicolumn{2}{c}{ Kelompok Kontrol } \\
\cline { 2 - 5 } & Frekuensi & $\%$ & Frekuensi & $\%$ \\
\hline Menikah & 33 & 82.5 & 29 & 72.5 \\
Janda & 7 & 17.5 & 11 & 27.5 \\
\hline Jumlah & $\mathbf{4 0}$ & $\mathbf{1 0 0}$ & $\mathbf{4 0}$ & $\mathbf{1 0 0}$
\end{tabular}

Sumber : Pengolahan Data, 2017

Berdasarkan tabel di atas dapat dijelaskan bahwa padakelompok eksperimen sebagian besar responden status pernikahan adalah menikah yaitu 33

\section{Analisis Univariat}

1. Variabel Pengetahuan

Skor nilai pengetahuan pada kelompok eksperimen dan kelompok kontrol adalah sebagai berikut orang $(82.5 \%)$ demikian pada kelompok kontrol sebagian besar responden status pernikahannya adalah menikah yaitu 29 orang $(72.5 \%)$. 
Tabel 5.Nilai Skor Pengetahuan Kelompok Eksperimen Yang Diberikan Pendidikan Kesehatan dan Kelompok Kontrol Yang diberikan Leaflet

\begin{tabular}{ccccccc}
\hline Variabel & N & Mean & SD & SE & $\begin{array}{c}\text { Min- } \\
\text { Max }\end{array}$ & CI 95\% \\
\hline Pengetahuan (Eks) & 40 & 12.83 & 1.678 & 0.265 & $10-16$ & $12.29-13.36$ \\
Pengetahuan (Kon) & 40 & 9.15 & 1.312 & 0.207 & $7-12$ & $8.73-9.57$ \\
\hline
\end{tabular}

Sumber Data : Hasil Pengolahan Data, 2017

Berdasarkan data di atas dapat dilihat bahwa skor rata-rata pengetahuan responden pada kelompok eksperimen adalah 12.83 , nilai standar deviasi 1.678 , nilai standar error 0.265 , nilai minimal 10 dan nilai maksimal 16 dengan nilai confidence interval antara 12.29-13.36.
Sedangkan pada kelompok kontrol nilai rata-rata pengetahuan adalah 9.15 , nilai standar deviasi 1.312, nilai standar error 0.207 , nilai minimal 7 dan nilai maksimal 12 dengan confidence interval antara 8.739.57 .

2. Variabel Minat

Skor nilai minat pada kelompok eksperimen dan kelompok kontrol adalah sebagai berikut:

Tabel 6.Nilai Skor Minat Kelompok Eksperimen Yang Diberikan Pendidikan Kesehatan dan Kelompok Kontrol Yang diberikan Leaflet

\begin{tabular}{ccccccc}
\hline Variabel & N & Mean & SD & SE & $\begin{array}{c}\text { Min- } \\
\text { Max }\end{array}$ & CI 95\% \\
\hline Minat (Eksperimen) & 40 & 52.75 & 8.682 & 1.373 & $38-68$ & $\begin{array}{c}49.97- \\
\text { Minat (Kontrol) }\end{array}$ \\
& 40 & \multirow{2}{*}{40.85} & 4.682 & 0.740 & $30-54$ & $\begin{array}{c}55.53 \\
\end{array}$ \\
& & & & & & $42.35-$ \\
\hline
\end{tabular}

Sumber Data : Hasil Pengolahan Data, 2017

Berdasarkan tabel.6 dapat dilihat bahwa skor rata-rata minat responden pada kelompok eksperimen adalah 52.75, nilai standar deviasi 8.682, nilai standar error 1.373 , nilai minimal 38 dan nilai maksimal 68 dengan nilai confidence interval antara 49.97-55.53. Sedangkan pada kelompok kontrol nilai rata-rata 
minat adalah 40.85 , nilai standar deviasi 4.682, nilai standar error 0.740 , nilai minimal 30 dan nilai maksimal 54 dengan confidence interval antara 39.35-42.35.

\section{Analisis Bivariat}

Tabel.7

Perbedaan Pengetahuan Kelompok Eksperimen Yang Diberikan Pendidikan Kesehatan dan Kelompok Kontrol Yang diberikan Leaflet di Wilayah Kelurahan Sepinggan Balikpapan

\begin{tabular}{|c|c|}
\hline $\begin{array}{c}\text { SE } \\
\text { Difference }\end{array}$ & $\begin{array}{c}\text { P- } \\
\text { value }\end{array}$ \\
\hline $\begin{array}{r}\text { Eksperim } \\
\text { Kontrol }\end{array}$ & $3.005-4.345$ \\
\hline $\begin{array}{l}\text { Sumber Data : Hasil Pengolahan Data } \\
\text { Tabel } 7 \text { menunjukkan bahwa selisih } \\
\text { rata-rata skor pengetahuan antara } \\
\text { kelompok eksperimen dan kelompok } \\
\text { kontrol adalah 3.678, hal ini menjelaskan } \\
\text { bahwa nilai rata-rata pengetahuan } \\
\text { kelompok eksperimen lebih tinggi } 3.675 \\
\text { dibandingkan dengan skor pengetahuan } \\
\text { kelompok kontrol. Nilai Standar Error } \\
\text { Difference 0.337 dimana nilai rentang } \\
\text { interval kepercayaan 95\% adalah 3.005 } \\
\text { sampai dengan 4.345. Dari hasil uji t } \\
\text { independent thitung }=10.914>t_{\text {tabel(n-2, } 12 a)=}= \\
\text { 1.991 dan nilai signifikan didapatkan }\end{array}$ & $\begin{array}{l}\text { nilai } p=0,000<\alpha 0,05 \text {, maka dapat } \\
\text { ditarik kesimpulan bahwa terdapat } \\
\text { perbedaan pengetahuan antara kelompok } \\
\text { yang diberikan pendidikan kesehatan } \\
\text { dengan kelompok yang diberikan leaflet } \\
\text { pada WUS di Wilayah Kelurahan } \\
\text { Sepinggan Balikpapan. Hasil penelitian } \\
\text { menunjukkan rata-rata nilai skor } \\
\text { pengetahuan pada kelompok yang } \\
\text { diberikan pendidikan kesehatan lebih } \\
\text { baik dibandingkan dengan rata-rata nilai } \\
\text { skor pengetahuan pada kelompok yang } \\
\text { diberikan leaflet. }\end{array}$ \\
\hline
\end{tabular}

Tabel.8 Perbedaan Minat Kelompok Eksperimen Yang Diberikan Pendidikan Kesehatan dan Kelompok Kontrol Yang diberikan Leaflet

\begin{tabular}{cccccc} 
Kelompok & $\begin{array}{c}\text { Mean } \\
\text { Difference }\end{array}$ & $\begin{array}{c}\text { SE } \\
\text { Difference }\end{array}$ & 95\% CI & t & P value \\
& & & & \\
\hline
\end{tabular}


Mahakam Midwifery Journal, Vol 2, No. 4, November 2018 : 292-311

\begin{tabular}{|c|c|}
\hline $\begin{array}{c}\text { Eksperimen } \\
\text { Kontrol }\end{array}$ & $8.795-15.005$ \\
\hline umber Data : Hasil Pengolahan Data & \\
\hline Tabel.8 menunjukkan & 8.795 sampai dengan 15.005. Dari \\
\hline selisih rata-rata skor pengetahuan & hasil uji $\mathrm{t}$ independent $t_{\text {hitung }}=7.630>$ \\
\hline antara kelompok eksperimen dan & $\mathrm{t}_{\text {tabel }(\mathrm{n}-2,1 / 2 \alpha)}=1.991$ dan nilai signifikan \\
\hline kelompok kontrol adalah 11.900 , hal & didapatkan nilai $\mathrm{p}=0,000<\alpha 0,05$, \\
\hline ini menjelaskan bahwa nilai rata-rata & maka dapat ditarik kesimpulan bahwa \\
\hline pengetahuan kelompok eksperimen & terdapat perbedaan minat \\
\hline lebih tinggi 11.900 dibandingkan & kelompok yang diberikan pendidikan \\
\hline dengan skor pengetahuan kelompok & kesehatan dengan kelompok yang \\
\hline kontrol. Nilai Standar & diberikan leaflet pada WUS di \\
\hline Difference 1.560 dimana nilai rentang & Kelurahan \\
\hline interval kepercayaan $95 \%$ adalah & Balikpapan. \\
\hline
\end{tabular}

\section{Pembahasan}

\section{Perbedaan Pengetahuan Tentang} Tes IVA anatara Kelompok Eksperimen dan Kelompok Kontrol.

sedangkan kelompok kontrol yang terdiri dari 40 responden diberikan leaflet, setelah itu dilakukan tes untuk mengetahui perbedaan ratarata skor pengetahuan pada kelompok eksperimen yang

Penelitian ini menggunakan dua kelompok perlakuan dimana kelompok eksperimen yang terdiri dari 40 responden diberikan pendidikan kesehatan tentang kanker serviks dan tes IVA diberikan pendidikan kesehatan dan rata-rata skor pengetahuan pada kelompok kontrol yang diberikan leaflet, adapun hasilnya adalah nilai rata-rata kelompok eksperimen lebih tinggi yaitu 12.83 
dibandingkan dengan kelompok yang diberikan leaflet yaitu 9.15 atau terdapat selisih 3.675. Hasil penelitian ini menunjukkan bahwa pendidikan kesehatan efektif dalam meningkatkan pengetahuan tentang kanker serviks dan tes IVA dibandingkan hanya diberikan leaflet.

Salah satu cara untuk meningkatkan perilaku kesehatan yakni melalui pendidikan kesehatan atau penyuluhan kepada wanita PUS agar terjadi perubahan perilaku. Pendidikan kesehatan terbukti efektif dalam meningkatkan perilaku kesehatan dengan meningkatnya pengetahuan tentang kanker serviks dan tes IVA (Wiharja, 2003).

Penelitian yang dilakukan oleh Herawati (2011) mengenai Pengaruh Penyuluhan Terhadap Peningkatan Pengetahuan Tentang Deteksi Dini Kanker Leher Rahim Pada Ibu-Ibu PKK Di Kelurahan Wirobrajan Tahun 2011 yang memberikan hasil bahwa penyuluhan mampu meningkatkan pengetahuan sebesar 3,2. Terdapat perbedaan peningkatan nilai ratarata pengetahuan sebelum dan sesudah diberikan penyuluhan sebesar 3,485714 dengan p-value< $(0,0000)$ yang berarti $\mathrm{p}$-value $<0,05$ sehingga perbedaan tersebut bermakna, yang artinya penyuluhan yang diberikan efektif dalam meningkatkan pengetahuan tentang deteksi dini kanker leher rahim dari pada metode ceramah pada ibu-ibu PKK di kelurahan Wirobrajan tahun 2011.

Penelitian ini selaras dengan penelitian yang dilakukan Wahyuni Indah Sawitri (2013) dengan judul penelitian Pengaruh Penyuluhan Kesehatan terhadap Pengetahuan dan Sikap Pencegahan Kanker Serviks pada Siswi di SMK Ma'arif 6 Ayah Kabupaten Kebumen.Tujuan penelitian ini untuk mengetahui pengaruh penyuluhan kesehatan terhadap pengetahuan dan sikap tentang pencegahan kanker serviks. Metode yang digunakan adalah pre experiment design dengan 
rancangan prestest-posttest with control group. Pada 36 Siswi (kelompok Eksperimen 18 siswa dan kelompok kontrol 18 siswa). Teknik pengambilan sampel dengan cara purposive sampling. Analisis data menggunakan Wilcoxon dan Man Whitney. Berdasarkan penelitian yang dilakukan terdapat perbedaan pengetahuan tentang pencegahan kanker serviks antara pre test dan post test pada kelompok perlakuan dilihat dari nilai $\mathrm{p}$-value $0,007<\alpha(0,05)$. Sedangkan pada kelompok kontrol tidak ada perbedaan pengetahuan tentang kanker serviks antara pre test dan post test dilihat dari $p$ value $0,109>\alpha(0,05)$. Terdapat pengaruh penyuluhan terhadap pengetahuan siswi tentang pencegahan kanker serviks dilihat dari nilai $\mathrm{p}$ value $0,0001<\alpha(0,05)$.

Berdasarkan data dapat dilihat sebelum diberikan pendidikan kesehatan, rata-rata pengetahuan responden 12.83 artinya rata-rata responden mengetahui 13 dari 17 pertanyaan yang diajukan tetapi pada kelompok kontrol rata-rata responden adalah 9.15 yang artinya responden mampu menjawab 9 dari 17 pertanyaan yang diajukan. Hal ini menjelaskan bahwa kelompok yang diberikan pendidikan kesehatanlebih baik pengetahuannya dibandingkan kelompok yang tidak diberikan pendidikan kesehatan.

Masalah yang ada di wilayah Kelurahan Sepinggan Balikpapan adalah kesadaran WUS untuk melakukan deteksi dini kanker serviks yang merupakan salah satu upaya pencegahan kanker serviks masih sangat rendah, masih banyak wanita yang tidak mau melakukan pemeriksaan karena merasa khawatir dengan hasil pemeriksaan yang akan diterima sehingga WUS memilih untuk tidak mengetahuinya sama sekali, padahal hal tersebut dapat merugikan WUS sendiri karena apabila penyakit kanker serviks terlambat diketahui, maka penyembuhannya akan sulit, membutuhkan waktu dan biaya yang besar. 
Menurut peneliti, masih Pengetahuan yang tidak lengkap banyaknya wanita yang memiliki pengetahuan tentang pencegahan kanker serviks dapat berasal dari instansi kesehatan dalam hal ini adalah Puskesmas, dimana Puskesmas tidak memiliki program rutin untuk memberikan informasi ataupun brosur-brosur tentang pencegahan kanker serviks, selama ini Puskesmas lebih mengutamakan pelayanan kesehatan ibu dan anak seperti kegiatan posyandu, $\mathrm{KB}$, perilaku hidup sehat dan bersih tetapi program-program pencegahan kanker serviks seperti vaksin ataupun pemeriksaan tes IVA di Puskesmas belum disosialisasikan di masyarakat sehingga masih banyak masyarakat yang tidak mengetahui masalah kanker serviks, penyebab, risiko, cara pencegahan dan pengobatan kanker serviks, selama ini informasi yang diperoleh tentang kanker serviks biasanya diperoleh dari pengalaman orang lain dengan berbagai macam cara pengobatan yang belum teruji kebenarannya.

justru menyebabkan wanita PUS takut untuk memeriksakan diri karena takut akan hasil pemeriksaan, padahal jika mereka mengetahui bahwa penyakit kanker serviks dapat diobati jika diketahui lebih dini, hal ini akan menimbulkan kesadaran untuk melakukan pemeriksaan lebih awal, tetapi karena pemahaman yang diperoleh masing tidak lengkap yang timbul justru ketakutan yang tidak mendasar.

\section{Perbedaan Pengetahuan Tentang Tes IVA anatara Kelompok Eksperimen dan Kelompok Kontrol.}

Hasil penelitian menunjukkan bahwa minat WUS pada kelompok eksperimen yang mendapatkan pendidikan kesehatan lebih tinggi dibandingkan dengan minat melakukan tes IVA pada kelompok kontrol yang hanya diberikan leaflet dimana kelompok eksperimen memiliki nilai ata-rata minat 
sebesar 52.75 lebih tinggi dibandingkan skor rata-rata kelompok kontrol yaitu 40.85, hal ini menjelaskan bahwa pendidikan kesehatan lebih efektif terhadap minat WUS untuk melakukan tes IVA dibandingkan WUS hanya diberikan leaflet.

Pendidikan kesehatan tentang kanker serviks dan tes IVA saat ni sangat penting mengingat semakin meningkatnya kasus kanker servisk dan rendahnya kesadaran WUS untuk melakukan deteksi dini. Novel (2010) menjelaskan bahwa kesadaran masyarakat untuk memeriksakan diri sejak dini dirasakan sangat rendah. Selain itu, masyarakat merasa pemeriksaan pap smear dianggap tabu, ibu merasa malu untuk melakukan pemeriksaan. Indikasinya adalah lebih dari $70 \%$ penderita yang datang ke Rumah Sakit sudah pada stadium lanjut.Seluruh masyarakat harusnya terlibat dalam upaya program pencegahan terhadap kanker serviks.Salah satu upaya untuk meningkatkan minat masyarakat yaitu dengan menggunakan pendidikan kesehatan. Penekanan konsep pendidikan kesehatan kesehatan lebih pada upaya mengubah perilaku sasaran agar berperilaku sehat terutama pada aspek kognitif (pengetahuan dan pemahaman sasaran), sehingga pengetahuan sasaran pendidikan kesehatan telah sesuai dengan yang diharapkan oleh penyuluh kesehatan maka penyuluhan berikutnya akan dijalankan sesuai dengan program yang telah direncanakan (Maulana, 2009).

Peran bidan sebagai salah satu tenaga kesehatan mempunyai kewajiban untuk memotivasi WUS dengan memberikan informasi tentang kanker serviks dan bahaya kanker serviks karena cara yang paling efektif dan efisien dalam pencegahan kanker serviks adalah dengan deteksi dini dengan pemeriksaan secara berkala, sehingga diperlukan pemahaman tentang deteksi dini kanker serviks yang dapat dilakukan secara 
sederhana, tidak sakit, dan penilaian laboratorium secara cepat, sehingga dapat menurunkan angka kesakitan dan kematian (Soehartono, 2010).

Menurut Hurlock (2008), faktor yang mempengaruhi minat diantaranya yaitu umur, pendidikan, pekerjaan dan staus pernikahan. Berdasarkan karakteristik responden paling banyak adalah berumur > 40 tahunbaik pada kelompok eskperimen dan kelompok kontrol sebesar $70 \%$. Menurut penelitian Mupepi etal. (2011) wanita yang berumur 25-34 tahun lebih bersedia melakukan skrining kanker serviks dibandingkan dengan wanita yang lebih tua, sedangkan menurut penelitian Sairafi et al(2007) wanita yang berumur 30-49 tahun lebih bersedia untuk melakukan skrining kanker serviks. Berdasarkan tingkat pendidikan, dapat diketahui bahwa responden terbanyak adalah pendidikan SMA baik pada keompk eskperimen dan kelompok kontrol . Menurut Hurlock (2008) pendidikan berpengaruh, sebab pendidikan yang tinggi cenderung akan mencari pengetahuan yang lebih luas. Pendidikan berkaitan dengan penguasaan pengetahuan, semakin tinggi tingkat pengetahuan maka akan semakin baik respon yang terbentuk terhadap suatu hal yang positif. Tingkat pendidikan juga memiliki hubungan yang bermakna dengan penerimaan skrining kanker serviks berdasarkan penelitian Priscilla et al. (2012).

Berdasarkan pekerjaan responden paling banyak yang tidak bekerja baik pada kelompok eksperimen dan kelompok kontrol.Pekerjaan berkaitan dengan minat seseorang untuk melakukan sesuatu dalam hal ini minat untuk melakukan tes IVA. Menurut Hurlock (2008) pekerjaan berpengaruh karena semakin baik latar belakang pekerjaan, maka minat seseorang akan cenderung semakin meningkat, begitu pula jika pekerjaan yang kurang baik maka seseorang akan membatasi minat untuk melakukan sesuatu. Hasil penelitian ini sesuai dengan 
penelitian yang dilakukan oleh Nurhasanah (2008) bahwa variabel karakteristik yang berpengaruh secara signifikan terhadap pemeriksaan tes IVA adalah umur, pendidikan dan pekerjaan.

Menurut penelitian Mupepi et al. (2011), penghasilan berpengaruh terhadap kesediaan skrining kanker serviks.Wanita yang berpenghasilan memiliki kemungkingan yang lebih besar untuk melakukan skrining kanker serviks dibandingkan dengan wanita yang bergantung terhadap penghasilan suaminya.

Penggunaan dan pemilihan metode penyuluhan yang tepat mempengaruhi tingkat keberhasilan transfer informasi. Menurut Effendy (2009), metode yang tepat dalam memberikan penyuluhan dapat mengembangkan komunikasi dua arah antara yang memberikan penyuluhan terhadap sasaran, sehingga sasaran dapat meningkatkan pemahaman terhadap pesan yang disampaikan.

Berdasarkan hasil penelitian ini dapat diambil kesimpulan bahwa pendidikan kesehatan sangat perlu dilakukan secara berkala di Balikpapan khususnya di wilayah Kelurahan Sepinggan mengingat dampaknya yang dapat menumbuhkan minat untuk melakukan deteksi dini kanker servik melalui tes IVA.

\section{SIMPULAN}

Berdasarkan hasil penelitian dan pembahasan, maka dapat diambil kesimpulan sebagai berikut: Karakteristik WUS di Wilayah Kelurahan Sepinggan Balikpapan pada kelompok eksperimen dan kelompok kontrol sebagian besar berusia $<40$ tahun, sebagian besar sama-sama memiliki latar belakang pendidikan SMA, sebagian besar memiliki latar belakang tidak bekerja/IRT dengan status menikah, gambaran pengetahuan WUS tentang kanker serviks dan deteksi dini dengan IVA test di wilayah Kelurahan Sepinggan Balikpapan pada kelompok eksperimen memiliki nilai rata-rata 12.83 , nilai standar deviasi 1.678 , nilai standar 
error 0.265 , nilai terendah 10 dan nilai tertinggi 16 sedangkan pada kelompok kontrol memiliki nilai rata-rata 9.15, nilai standar deviasi 1.312, nilai standar error 0.207 , nilai terendah 7 dan nilai tertinggi 12, gambaran minat WUS terhadap deteksi dini dengan IVA test di wilayah Kelurahan Sepinggan Balikpapan pada kelompok eksperimen memiliki nilai rata-rata 52.75, nilai standar deviasi 4.682, nilai standar error 1.373, nilai terendah 38 dan nilai tertinggi 68 sedangkan pada kelompok kontrol memiliki nilai rata-rata 40.855 , nilai standar deviasi 1.312 , nilai standar error 0.740 , nilai terendah 30 dan nilai tertinggi 54 , ada perbedaan Pengetahuan WUS tentang kanker serviks dan deteksi dini dengan IVA di wilayah Kelurahan Sepinggan Balikpapan pada kelompok yang diberikan Pendidikan Kesehatan dan kelompok yang diberikan leaflet/brosur ditunjukkan dengan nilai $\mathrm{p}$ value 0,000 . Ada perbedaan minat WUS melakukan pemeriksaan IVA di wilayah Kelurahan Sepinggan Balikpapan pada kelompok yang diberikan Pendidikan Kesehatan dan kelompok yang diberikan leaflet/brosur ditunjukkan dengan nilai $\mathrm{p}$ value 0.000 .

\section{UCAPAN TERIMA KASIH}

Terimakasih penulis ucapkan kepada institusi yang telah memberikan kesempatan untuk melakukan penelitian ini, kepada staf dan dosen pembimbing serta penguji utama yang telah sangat membantu dalam penulisan penelitian ini, kepada teman-teman sejawat dan orangtua serta keluarga yang selalu memberikan motivasi dalam jalannya penelitian. 
Mahakam Midwifery Journal, Vol 2, No. 4, November 2018 : 292-311

\section{DAFTAR PUSTAKA}


RI, D. (2007). Buku acuan pencegahan kanker leher rahim dan kanker payudara. Departemen Kesehatan. Jakarta.

Efendi, Feri. (2009). Keperawatan Kesehatan Komunitas. Jakarta : salemba Medika

Herawati. (2011). Pengaruh Penyuluhan Terhadap Peningkatan Pengetahuan Tentang Deteksi Dini Kanker Leher Rahim Pada Ibu-Ibu PKK Di Kelurahan Wirobrajan Tahun 2011. Jurnal permata indonesia

Hurlock, E. B., Istiwidayanti, Sijabat, R. M., \& Soedjarwo. (1990). Psikologi perkembangan: Suatu pendekatan sepanjang rentang kehidupan. Erlangga, Jakarta.

Koran Kaltim Pos. 2017. Meningkatnya Jumlah Kanker Serviks di Indonesia. 5 Februari . Halaman 4. Balikpapan.

Maulana, H. D., Sos, S., \& Kes, M. (2009). Promosi kesehatan. EGC.

Notoatmodjo, S. (2010). Metodologi penelitian kesehatan.. Jakarta : PT RinekaCipta
Novel, S. S., Safitri, R., \& Nuswantara, S. (2010). Deteksi Dini Kanker Serviks Melalui Uji sitologi dan DNA HPV.Cermin Dunia Kedokteran, 37(2), 175.

Busingye, P., Nakimuli, A., Nabunya, E., \& Mutyaba, T. (2012). Acceptability of cervical cancer screening via visual inspection with acetic acid or Lugol's iodine at Mulago Hospital, Uganda. International Journal of Gynecology \& Obstetrics, 119(3), 262-265.

Al Sairafi, M., \& Mohamed, F. A. (2009). Knowledge, attitudes, and practice related to cervical cancer screening among Kuwaiti women. Medical Principles and Practice, 18(1), 35-42.

Soehartono.

(2010). Sitologi Vagina.Jakarta :Bal ai FKUI.

Wahyuni Indah Sawitri. (2013). Pengaruh Penyuluhan Kesehatan terhadap Pengetahuan dan Sikap Pencegahan Kanker Serviks pada Siswi di SMK Ma'arif 6 Aliyah, diakses : 12 Agustus 2017. 
Mahakam Midwifery Journal, Vol 2, No. 4, November 2018 : 292-311

Wiharja, Saleh. (2016). Tes IVA.

http//www.pdpersi.co.id. diakses:

21/8/2016 